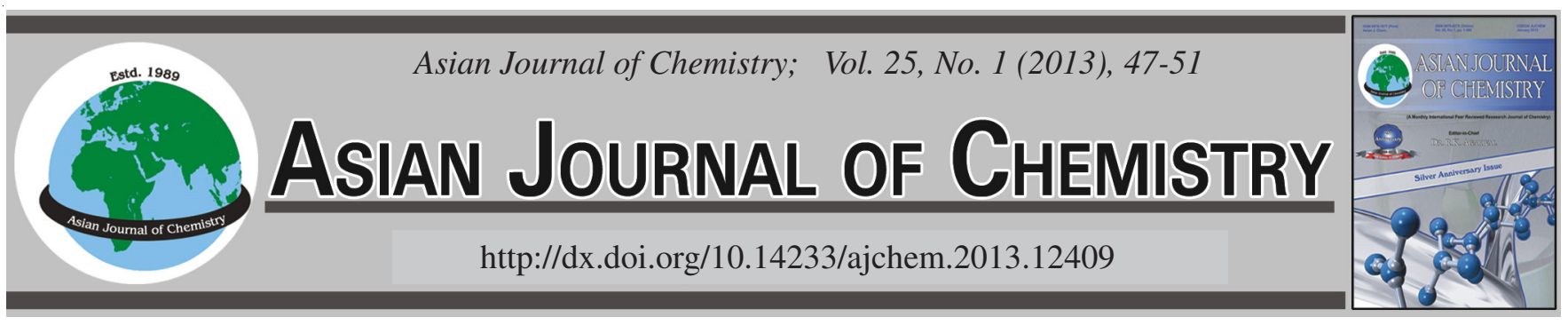

\title{
Composition, Antimicrobial and Antioxidant Activities of Artemisia deserti Kracsh Essential Oil from Iran
}

\author{
M. KAZEmi ${ }^{1, *}$, M. Dakhili ${ }^{1}$, A. DadKhah ${ }^{1}$, M. FAdAEIAN $^{1}$ and S. ShafiZAdeh ${ }^{2}$
}

${ }^{1}$ Department of Applied Chemistry and Faculty of Medicine, Qom Branch, Islamic Azad University, Qom, Iran ${ }^{2}$ Department of Applied Chemistry, Shahr-e-Rey Branch, Islamic Azad University, Shahr-e-Rey, Iran

*Corresponding author: E-mail: smkazemit@yahoo.com

(Received: 15 July 2011;

Accepted: 9 July 2012)

AJC-11818

Several Artemisia species have medicinal importance and are useful in traditional medicine for the treatment of a variety of diseases and
complaints. The hydro-distilled essential oil of Artemisia deserti was investigated by combination of GC-FID and GC/MS methods.
Between 43 identified compounds, camphor $(20.1 \%)$, trans-thujone $(17.8 \%)$ and 1,8 -cineole $(10.1 \%)$ were the main components. The
antimicrobial activity of the oil was evaluated by a disc diffusion method. The oil has shown maximum zone of inhibition against
Pseudomonas aeruginosa and Staphylococcus aureus. As the other results, Staphylococcus aureus was the most sensitive microorganisms
to the essential oil (having minimum inhibitory concentration (MIC) value 0.625 and minimum bactericidal concentration (MBC) value
$1.25 \mathrm{mg} / \mathrm{mL}$ ). The oil antioxidant activities were measured by DPPH assay and $\beta$-carotene-linoleic acid test. The essential oil significantly
reduced the concentration of DPPH free radical $(57.2 \%)$, with an efficacy higher than that of Trolox (48.1\%). Also, a $50 \%$ inhibition was
noted in formation of peroxidation products in $\beta$-carotene bleaching test.

Key Words: Artemisia deserti, Compositae, Essential oil composition, Camphor, trans-Thujone, 1,8-Cineole, Antimicrobial activity, Antioxidant activity.

\section{INTRODUCTION}

The genus Artemisia (Compositae) contains small herbs or shrubs found in northern temperate regions. Thirty-four species of the genus Artemisia are found in Iran, of which two are endemic viz., A. melanolepis Boiss. and A. kermanensis Podl. ${ }^{1}$. Several Artemisia species have medicinal importance and are useful in traditional medicine for the treatment of a variety of diseases and complaints. A. апnиа is a traditional medicinal herb of China. It is presently being cultivated on a commercial scale in China and Vietnam for its antimalaria sesquiterpene lactone artemisinin ${ }^{2}$. In addition, A. аппиа is valued for its essential oil ${ }^{3}$. Various medical applications have been ascribed to the essential oils of Artemisia ${ }^{4-6}$ for example A. dracunculus has been used orally as an antiepileptic remedy in which its anticonvulsant potential has been assessed ${ }^{5}$. Numerous reports have appeared in the literature on the essential oils and its antimicrobial and antioxidant activities of different species of Artemisia ${ }^{7-21}$. In previous studies on $A$. deserti herb, some compounds such as germaceranolide, guanolide, monoterpenes and sesquiterpenes, were elucidated from extract of the aerial parts ${ }^{22}$. The essential oil of $A$. desert $i$ areal parts was also investigated ${ }^{21,21}$. In the present study, for the first time, the antimicrobial and antioxidant activities of the essential oil of $A$. deserti are reported.

\section{EXPERIMENTAL}

The aerial parts of $A$. deserti were collected during the flowering stage in Simindasht area, province of Tehran, Iran, in August 2009. Voucher specimens (No. 59084) have been deposited at the Herbarium of the Research Institute of Forests and Rangelands (TARI), Tehran, Iran.

Isolation of the oil: The aerial parts $(134 \mathrm{~g})$ of $A$. deserti of the plant were subjected separately to hydro-distillation using a Clevenger-type apparatus for $3 \mathrm{~h}$. After decanting and drying over anhydrous sodium sulfate, the corresponding yellowish coloured oils were recovered in yields of $0.2 \% \mathrm{w} / \mathrm{w}$, respectively. The sample were then kept in bottles covered in aluminium foil at $4{ }^{\circ} \mathrm{C}$ to prevent the negative effect of light, especially direct sunlight.

GC-FID: Gas chromatography-flame ionization detector analysis was performed on a Shimadzu 15A gas chromatograph equipped with a split/splitless (ratio 1:30), injector $\left(250^{\circ} \mathrm{C}\right.$ ) and a flame ionization detector $\left(250^{\circ} \mathrm{C}\right)$. Nitrogen was used as carrier gas $(1 \mathrm{~mL} / \mathrm{min})$ and the capillary column used was DB-5 $(50 \mathrm{~m} \times 0.2 \mathrm{~mm}$, film thickness $0.32 \mu \mathrm{m})$. The column 
temperature was kept at $60{ }^{\circ} \mathrm{C}$ for $3 \mathrm{~min}$ and then heated to $220{ }^{\circ} \mathrm{C}$ with a $5{ }^{\circ} \mathrm{C} / \mathrm{min}$ rate and kept constant at $220{ }^{\circ} \mathrm{C}$ for $5 \mathrm{~min}$. Relative percentage amounts were calculated from peak area using a Shimadzu C-R4A chromatopac without the use of correction factors.

GC/MS: Analysis was performed using a HewlettPackard 5973 with a HP-5MS column $(30 \mathrm{~m} \times 0.25 \mathrm{~mm}$, film thickness $0.25 \mu \mathrm{m})$. The column temperature was kept at $60{ }^{\circ} \mathrm{C}$ for $3 \mathrm{~min}$ and programmed to $220^{\circ} \mathrm{C}$ at a rate of $5^{\circ} \mathrm{C} / \mathrm{min}$ and kept constant at $220^{\circ} \mathrm{C}$ for $5 \mathrm{~min}$. The flow rate of helium as carrier gas was $(1 \mathrm{~mL} / \mathrm{min})$. MS were taken at $70 \mathrm{eV}$, mass range, 30 to 350 amu and scan time 2 scans/sec.

Identification of components: The compounds were identified by comparison of KI from DB- 5 column with those reported in the literature and by comparison of their mass spectra with either the Wiley library or with published mass spectra $^{23-25}$. The Kovats indices for all the components were determined according to the van Den Dool method, using $n$-alkanes as standards ${ }^{26}$.

Microorganisms: The bacteria included Bacillus cereus (ATCC 6633), Bacillus subtilis (ATCC 9372), Enterobacter spp, Escherichia coli (ATCC 25922), Citrobacter spp, Klebsiella pneumoniae (ATCC 27736), Pseudomonas aeruginosa (ATCC 27852) and Staphylococcus aureus (ATCC 25923) and fungi, Aspergillus niger (ATCC 9142) and Candida albicans (ATCC 6258). The microorganisms were obtained from the Research Center of Science and Industry, Tehran, Iran.

Antimicrobial tests: The antimicrobial activity of the essential oil was evaluated by a disc diffusion method using Mueller-Hinton and Sabouraud Dextrose agar respectively ${ }^{27,28}$. A suspension of the tested microorganism $(0.1 \mathrm{~mL}$ of a suspension of the tested microorganisms, containing $1.5 \times 10^{8}(\mathrm{CFU} /$ $\mathrm{mL}$ ) was spread on the solid media plates. Mueller-Hinton and Sabouraud Dextrose agar sterilized in a flask and cooled to $45-50{ }^{\circ} \mathrm{C}$ were distributed to sterilized petri dishes with a diameter of $9 \mathrm{~cm}(15 \mathrm{~mL})$. A serial dilution of the oil was prepared in Mueller-Hinton and Sabouraud Dextrose Broth for bacteria and fungi respectively. The filter paper discs $(6 \mathrm{~mm}$ in diameter) were individually impregnated with $15 \mu \mathrm{L}$ of the A. deserti essential oil and then placed onto the agar plates which had previously been inoculated with the tested microorganisms. The plates were inoculated with bacteria incubated at $37^{\circ} \mathrm{C}$ for $24 \mathrm{~h}$ and at $28^{\circ} \mathrm{C}$ for $72 \mathrm{~h}$ for the fungal strains. Ethanol $(95 \%)$ was used as a negative control in all the plates while ampicillin (10 mg/disc), gentamycin (10 mg/disc) for bacteria and fluconazol (20 mg/disc) were used as positive controls. The diameters of the inhibition zones were measured in millimetres.

For MIC assay, two controls were included with each batch of test. The first was a negative control, which contained the test material but not the organisms to check for contamination of the test material ${ }^{29}$. The positive control contained microorganisms without the test material. The standardized suspension of bacteria and fungi were inoculated in to each tube and the final concentration in them was adjusted to $1.0 \times 10^{6} \mathrm{CFU} /$ $\mathrm{mL}$ for strains. The tubes were incubated at $37^{\circ} \mathrm{C}$ and $24 \mathrm{~h}$ for bacteria and at $30{ }^{\circ} \mathrm{C}$ and $48-72 \mathrm{~h}$ for fungi. The lowest oil concentration, which completely inhibited microbial growth, was the minimum inhibitory concentration (MIC) when compared to the control. To determine the minimum bactericidal concentration (MBC) and minimum fungicidal concentration (MFC), for each set of test tubes in the MIC determination, a loopful of broth was collected from those tubes which did not show any growth and inoculated on Mueller-Hinton agar (for bacteria) and Sabouraud Dextrose Broth agar (for fungi) by streaking. Tubes inoculated with bacteria and fungi were then incubated at $37^{\circ} \mathrm{C}$ for 24 hours and $30^{\circ} \mathrm{C}$ for $48-72 \mathrm{~h}$, respectively. After incubation the concentration at which no visible growth was seen was noted as MBC (for bacteria) and MFC (for fungi). All the experiments were carried out in triplicate and the mean calculated.

Radical-scavenging capacity (DPPH assay) of the oil: The hydrogen atom or electron donation abilities of the essential oil were measured from the bleaching of the purplecoloured methanol solution of 2,2-diphenylpicrylhydrazyl (DPPH). This spectrophotometric assay uses the stable radical DPPH as a reagent ${ }^{30}$. In order to find out the effective dose of oil, different concentrations (0, 5, 10 and $20 \% \mathrm{v} / \mathrm{v}$ in methanol) were added to DPPH reaction mixture and the concentrationdependent inhibition in DPPH radical scavenging capacity was recorded (data not shown). Based on this, further experiments were carried out with $20 \%(\mathrm{~V} / \mathrm{V})$ of the oil. Then, $50 \mu \mathrm{L}$ of the essential oil in methanol were added to $5 \mathrm{~mL}$ of DPPH solution (0.004 \% DPPH in methanol). Trolox ( $1 \mathrm{mM}, 0.5$ $\mathrm{mM}$ and $0.25 \mathrm{mM}$ ), a stable antioxidant, was used as reference. After incubation for $0.5 \mathrm{~h}$ at room temperature, the absorbance was read against the blank at $517 \mathrm{~nm}$. The following formula was used to estimate the inhibitory effects of the oil extract in percent $(\mathrm{I} \%)$ : I \% $=\left(\mathrm{A}_{\text {blank }}-\mathrm{A}_{\text {sample }} / \mathrm{A}_{\text {blank }}\right) \times 100$. where, $\mathrm{A}_{\text {blank }}$ is the absorbance of the control reagent (containing all reagents except the test compound) and $\mathrm{A}_{\text {sample }}$ is the absorbance of the test compound. All the assays were carried out in triplicate.

$\boldsymbol{\beta}$-Carotene-linoleic acid assay of the oil: Antioxidant activity of the essential oil was determined using the $\beta$-carotene bleaching test as described by Taga et al. ${ }^{31}$. Approximately 10 $\mathrm{mg}$ of $\beta$-carotene (type I synthetic) was dissolved in $10 \mathrm{~mL}$ of chloroform. Two milliliters of the carotene-chloroform solution was pipetted into a boiling flask containing $20 \mathrm{mg}$ linoleic acid and $200 \mathrm{mg}$ Tween 40 . Chloroform was removed using a rotary evaporator at $40^{\circ} \mathrm{C}$ for $5 \mathrm{~min}$. Then, the residue was dissolved in $50 \mathrm{~mL}$ of distilled slowly with vigorous agitation, to form an emulsion. Five milliliters of the emulsion were added to a tube containing $0.2 \mathrm{~mL}$ of essential oil solution, prepared according to Choi et al. ${ }^{32}$. The absorbance was immediately measured at $470 \mathrm{~nm}$ against a blank, consisting of an emulsion without $\beta$-carotene. The tubes were placed in a water bath at $50{ }^{\circ} \mathrm{C}$ and the oxidation of the emulsion was monitored spectrophotometrically by measuring absorbance at $470 \mathrm{~nm}$ over a $1 \mathrm{~h}$. A sample containing $0.2 \mathrm{~mL}$ of ethanol instead of essential oils was used as control. Butylated hydroxyl toluene (BHT), a stable antioxidant, was used as a synthetic reference. The antioxidant activity was expressed as inhibition percentage with reference to the control after $1 \mathrm{~h}$ of incubation, using the following equation:

$$
\mathrm{AA}=\frac{100(\mathrm{DRC}-\mathrm{DRS})}{\mathrm{DRC}}
$$


where $\mathrm{AA}=$ antioxidant activity, $\mathrm{DRC}=$ degradation rate of the control $=[\ln (\mathrm{a} / \mathrm{b}) / 60], \mathrm{DRS}=$ degradation rate in presence of the sample $=[\ln (\mathrm{a} / \mathrm{b}) / 60], \mathrm{a}=$ absorbance at time $0, \mathrm{~b}=$ absorbance after $1 \mathrm{~h}$.

\section{RESULTS AND DISCUSSION}

The volatile constituents obtained from aerial parts of $A$. deserti are listed in Table-1 in which the percentage and retention indices of the components are given. At it is shown from Table-1, analysis of the aerial parts oil of $A$. deserti resulted in the identification of 43 constituents, representing $97.2 \%$ of the oil. The main components of the oil were camphor $(20.1 \%)$, trans-thujone $(17.8 \%)$ and 1,8-cineole (10.1\%). The aerial parts of $A$. deserti oil were found to be rich in regards to oxygenated monoterpenes $(71.4 \%)$ while hydrocarbon monoterpenes $(12.5 \%)$ and oxygenated sesquiterpenes $(10.5 \%)$ were the minor fractions. This sample was poor in other compounds $(2.8 \%)$ and sesquiterpene hydrocarbons (trace).

In some studies about the essential oils of other Artemisia species, 1,8-cineole and bornane derivatives were reported as the main constituents.1,8-Cineole $(27.8,25.7,19.0,14.3 \%)$ and camphor $(37.9,35.0,44,45.5 \%)$ were obtained to be major constituents of the oils of $A$. scoparia ${ }^{12}$, A diffusa $^{13}, A$. sieberi $^{14}$ and $A$. aucheri ${ }^{15}$, respectively.

In other reports, thujane derivatives were reported as the main constituents. These compounds were obtained to be major components of the oils of A. absinthium ${ }^{12}$, A. khorassanica ${ }^{16}$, A. herba-alba ${ }^{17} A$. fragrans $^{18}$ and $A$. verlotiorum ${ }^{19}$. In previous researches, the essential oils of $A$. deserti areal parts were investigated. Ahmadi et al. ${ }^{20}$ and Rustaiyan et al. ${ }^{21}$ reported piperiton $(52.0 \%$ and $8.6 \%)$, camphor $(15.7 \%$ and $45.5 \%)$ and 1,8-cineole (11.8 and $16.7 \%$ ) as the major components, respectively while in present work, piperitone was not observed.

Results of the antimicrobial activity and also the MIC, MBC and MFC of the oil are shown in Table-2. The oil has shown maximum zone of inhibition against Pseudomonas aeruginosa and Staphylococcus aureus. Staphylococcus aureus was the most sensitive microorganisms to the essential oil (having MIC value 0.625 and $\mathrm{MBC}$ value $1.25 \mathrm{mg} / \mathrm{mL}$ ). Previous studies showed that camphor and 1,8-cineole are well-known antimicrobial compounds isolated from different plant species ${ }^{33,34}$. The moderate antimicrobial activity of $A$. deserti oil could be associated with camphor and 1,8-cineole. In similar research, the composition of the essential oil obtained from Iranian $A$. апnи $\mathrm{L}$. was analyzed by GC and GC/MS ${ }^{7}$. Thirty-two components were identified in the essential oil with camphor (48\%), 1,8-cineole (9.39\%), camphene $(6.98 \%)$ and spathulenol (4.89 $\%$ ) as major components. The essential oil was evaluated for antibacterial and antifungal activities. The activity was more pronounced against fungal organisms than against Grampositive and Gram-negative bacteria. In present study, maximum activity has been observed against fungal microorganisms such as Candida albicans. Likewise, moderate inhibitory activities of the oil against Staphylococcus aureus and Echerichia coli have been determined (with MIC value 32 and $64 \mathrm{mg} / \mathrm{mL}$ respectively). In other study, the chemical composition of the essential oil from A. iwayomogi Kitamura
TABLE-1

PERCENTAGE COMPOSITION OF THE AERIAL PARTS OF $A$. deserti OIL

\begin{tabular}{|c|c|c|}
\hline Compound & $\mathrm{KI}^{\mathrm{a}}$ & $(\% \mathrm{w} / \mathrm{w})^{\mathrm{b}}$ \\
\hline Heptane & 700 & $\mathrm{t}$ \\
\hline Octane & 800 & $\mathrm{t}$ \\
\hline Santolina trien & 909 & $\mathrm{t}$ \\
\hline$\alpha$-Thujene & 930 & $\mathrm{t}$ \\
\hline$\alpha$-Pinene & 939 & 4.5 \\
\hline Camphene & 954 & 5.4 \\
\hline Sabinene & 975 & 1.2 \\
\hline$\beta$-Pinene & 979 & 0.7 \\
\hline Decane & 1000 & $\mathrm{t}$ \\
\hline$\alpha$-Terpinene & 1017 & $\mathrm{t}$ \\
\hline p-Cymene & 1025 & 2.3 \\
\hline 1,8-Cineole & 1031 & 10.1 \\
\hline$\gamma$-Terpinene & 1060 & 0.7 \\
\hline cis-Sabinene hydrate & 1070 & $\mathrm{t}$ \\
\hline Terpinolene & 1089 & $\mathrm{t}$ \\
\hline Linalool & 1091 & $\mathrm{t}$ \\
\hline$\alpha$-Thujone & 1102 & 0.8 \\
\hline trans-Thujone & 1114 & 17.8 \\
\hline Chrysanthenone & 1128 & 1.0 \\
\hline iso-3-Thujamol & 1133 & $\mathrm{t}$ \\
\hline trans-Verbenol & 1145 & 4.6 \\
\hline Camphor & 1146 & 20.1 \\
\hline Pinocarvone & 1162 & 2.0 \\
\hline trans-Chrysanthenol & 1164 & 7.8 \\
\hline Terpinen-4-ol & 1177 & 1.5 \\
\hline$\alpha$-Terpineol & 1188 & 2.0 \\
\hline Myrtenol & 1194 & $\mathrm{t}$ \\
\hline Myrtenal & 1196 & $\mathrm{t}$ \\
\hline Verbenone & 1205 & 0.8 \\
\hline Carvone & 1243 & $\mathrm{t}$ \\
\hline Chrysanthenyl acetate & 1265 & 0.8 \\
\hline trans-Patchenol & 1331 & $\mathrm{t}$ \\
\hline Neryl acetate & 1362 & $\mathrm{t}$ \\
\hline trans-Methyl cinnamate & 1379 & 0.5 \\
\hline cis-Jasmone & 1394 & 2.1 \\
\hline Artedouglasia oxide C & 1524 & 1.5 \\
\hline Artedouglasia oxide A & 1536 & 2.2 \\
\hline Artedouglasia oxide D & 1561 & $\mathrm{t}$ \\
\hline Davanone B & 1566 & 3.4 \\
\hline Spathulenol & 1578 & 1.5 \\
\hline Caryophyllene oxide & 1583 & 1.0 \\
\hline$\beta$-Oplopenone & 1608 & 0.9 \\
\hline Total & - & 97.2 \\
\hline Group components & - & - \\
\hline Monoterpene hydrocarbones & - & 12.5 \\
\hline Oxygenated monoterpenes & - & 71.4 \\
\hline Sesquiterpene hydrocarbones & - & $\mathrm{t}$ \\
\hline Oxygenated sesquiterpenes & - & 10.5 \\
\hline Other components & - & 2.8 \\
\hline
\end{tabular}

was analyzed by means of GC and GC/MS ${ }^{8}$. Eighty-five constituents were identified representing $96.23 \%$ of the total oil. Camphor (19.31\%), 1,8-cineole (19.25\%), borneol (18.96 $\%)$, camphene $(4.64 \%)$ and $\beta$-caryophyllene $(3.46 \%)$ were found to be the major components. Furthermore, the oil exhibited antibacterial activity against six Gram-(+) and six Gram-(-) bacteria. 
TABLE-2

ANTIMICROBIAL ACTIVITY OF A. deserti OIL AND ANTIBUTICS AGAINST STANDARD MICROORGANISMS

\begin{tabular}{|c|c|c|c|c|c|c|c|}
\hline \multirow{2}{*}{ Microorganisms } & \multicolumn{4}{|c|}{ Inhibition zone $(\mathrm{mm})$} & \multirow{2}{*}{ MIC } & \multirow{2}{*}{ MBC } & \multirow{2}{*}{ MFC } \\
\hline & Oil & AMP & GEN & FLU & & & \\
\hline Bacillus cereus (ATCC 6633) & NI & NI & $20.1 \pm 0.7$ & ND & 2.50 & 5.00 & - \\
\hline Bacillus subtilis (ATCC 6633) & NI & $25.2 \pm 0.7$ & $20.3 \pm 0.8$ & ND & 2.50 & 5.00 & - \\
\hline Citrobacter $\mathrm{spp}$ & NI & $23.4 \pm 0.4$ & $21.7 \pm 0.7$ & ND & ND & ND & - \\
\hline Entrobacter spp & NI & $10.3 \pm 0.6$ & $20.2 \pm 0.5$ & ND & 2.50 & 5.00 & - \\
\hline Escherichia coli (ATCC 25922) & NI & NI & $25.1 \pm 0.5$ & ND & 1.25 & 2.50 & - \\
\hline Klebsiella pneuтопiae (ATCC 27736) & NI & NI & $20.3 \pm 0.4$ & ND & 2.50 & 5.00 & - \\
\hline Pseudomonas aeruginosa (ATCC 27852) & $10.1 \pm 0.4$ & NI & $20.4 \pm 0.2$ & ND & 2.50 & 5.00 & - \\
\hline Staphylococcus aureus (ATCC 25923) & $10.3 \pm 0.2$ & NI & $25.3 \pm 0.2$ & ND & 0.625 & 1.25 & - \\
\hline Aspergillus niger (ATCC 9142) & ND & ND & ND & $20.1 \pm 1.1$ & 2.50 & - & 2.50 \\
\hline Candida albicans (ATCC 6258) & $\mathrm{NI}$ & ND & ND & $18.3 \pm 0.3$ & 2.50 & - & 5.00 \\
\hline
\end{tabular}

NI: no inhibition, ND: not determined, AMP: ampicillin, GEN: gentamycin, FLU: fluconazol, MIC: minimum inhibitory concentration, MBC: minimum bactericidal concentration, MFC: minimum fungicidal concentration, MIC, MBC and MFC of compounds are indicated in $\mathrm{mg} / \mathrm{mL}$. Values are means of three replications \pm SD

The antioxidant properties of the $A$. deserti essential oil measured by DPPH and $\beta$-carotene bleaching assays are presented in Fig. 1. When compared to a standard antioxidant agent, i.e. Trolox, it was found that the essential oil significantly reduced the concentration of DPPH free radical $(57.2 \%)$, with an efficacy higher than that of Trolox (48.1\%). Likewise, a $50 \%$ inhibition was noted in formation of peroxidation products in $\beta$-carotene bleaching test (Fig. 1). This result together with the oil composition may suggest that antioxidant activities of the oils are likely attributable to its principle compounds (camphor) and phenolic compounds ${ }^{31}$. Phenolic compounds such as thymol and carvacrol show potent antioxidant and DPPH radical scavenging activities ${ }^{35}$. The weak antioxidant activities of the non-phenolic components were also supported by other studies on essential oils of Artemisia species such as A. absinthium, A. biennis, A. cana, A. dracunculus, A. frigida, A. longifolia and A. ludoviciana ${ }^{9}$. In similar report, the volatile components of the aerial parts of $A$. judaica were isolated via hydrodistillation and analyzed by $\mathrm{GC} / \mathrm{MS}^{10}$. Piperitone (45\%), trans-ethyl cinnamate $(20.8 \%)$ and ethyl3 -phenyl propionate $(11 \%)$ were the predominant components, followed by spathulenol $(6.27 \%)$, cis-ethyl cinnamate (5.64\%), 2,6-dimethyl phenol (1.39\%) and methyl cinnamate $(1.06 \%)$. The oil showed antioxidative activity, determined by thiocyanate and scavenging effect on 1,2-diphenyl picrylhydrazyl (DPPH) methods. Its activity related to the

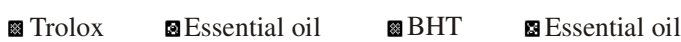

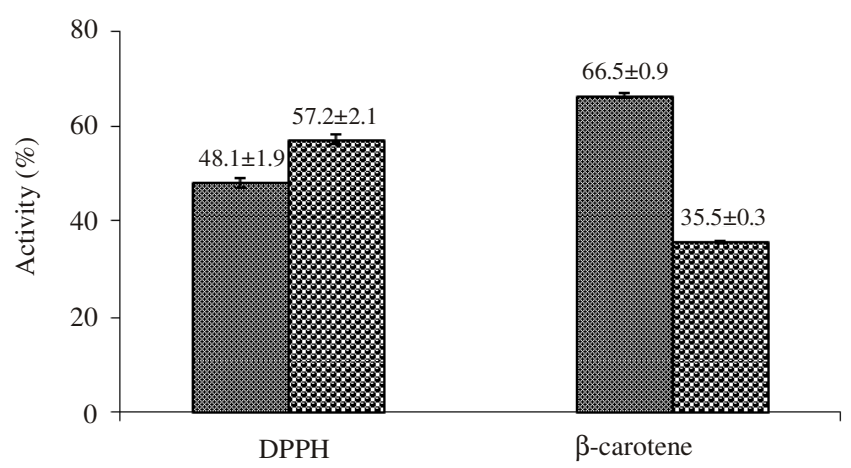

Fig. 1. Free radical-scavenging and antioxidant activities of $A$. deserti essential oil in comparison with those of the references presence of 2,6-dimethyl phenol (1.39\%) and camphor $(0.38 \%)$. In recent research, the essential oil from the leaves and flowers of $A$. herba alba were extracted by hydrodistillation and analyzed by $\mathrm{GC}$ and $\mathrm{GC} / \mathrm{MS}^{11}$. The major constituents were identified by cis-chrysantenyl acetate $(10.60 \%)$, the sabinyl acetate $(9.13 \%)$ and the $\alpha$-thujone $(8.73 \%)$. The oil was found to have an interesting antioxidant activity as evaluated by the DPPH and the $\beta$-carotene bleaching methods. The antimicrobial activities of $A$. herba alba oil were evaluated against six bacterial strains and three fungal strains by the agar diffusion method. The essential oil exhibited a strong growth inhibitory activity on all the studied fungi.

\section{Conclusion}

In this research, we have identified 43 mono and sesquiterpenes constituents from $A$. deserti essential oil. The moderate antimicrobial activity of $A$. deserti oil could be associated with main components. Also, the antioxidant activities of the oil may be due to the presence of phenolic compounds used for traditional applications. Therefore, the essential oil of $A$. desert $i$ can be used as medicinal plant in traditional applications because it has main components such as camphor and 1,8cineole with potent antimicrobial and antioxidant activities.

\section{ACKNOWLEDGEMENTS}

This research supported by Department of Applied Chemistry, Islamic Azad University, Shahr-e-Rey Branch as a M.Sc. Thesis.

\section{REFERENCES}

1. V. Mozaffarian, A Dictionary of Iranian Plant Names, Farhang Moaser Publishers, Tehran, Iran (1996).

2. X.D. Luo and C.C. Shen, Med. Res. Rev., 7, 29 (1987).

3. H.J. Woerdenbag, R. Bos, M.C. Salomons, H. Hendriks, N. Pras and T.M. Malingré, Flav. Frag. J., 8, 131 (1993).

4. J.D. Cha, S.E. Moon, H.Y. Kim, J.C. Lee and K.Y. Lee, Immunol. Invest., 38, 483 (2009).

5. C. Sinico, A. De Logu, F. Lai, D. Valenti, M. Manconi, G. Loy, L. Bonsignore and A.M. Fadda, Eur. J. Pharm. Biopharm., 59, 161 (2005).

6. M. Sayyah, L. Nadjafinia and M. Kamalinejad, J. Ethnopharmacol., 94, 283 (2004).

7. M.R. Verdian-rizi, Pharmacog. Res., 1, 21 (2009).

8. C.U. Hong, J. Korean Soc. Appl. Bio. Chem., 47, 124 (2004).

9. D. Lopez-lutz, D.S. Alviano, C.S. Alviano and P.P. Kolodziejczyk, Phytochemistry, 69, 732 (2008). 
10. F. Khaled, A.H. El-Massry and A.F. El-Ghorab, Food Chem., 79, 331 (2002).

11. S. Zouari, N. Zouari, N. Fakhfakh, A. Bougatef, M.A. Ayadi and M. Neffati, J. Med. Plants Res., 4, 871 (2010).

12. D.D. Han and K.H. Row, Asian J. Chem., 22, 2711 (2010).

13. K. Khazraei-Alizadeh and A. Rustaiyan, J. Essent. Oil Res., 13, 185 (2001)

14. P. Weyerstahl, S. Schneider, H. Marschall and A. Rustaiyan, Flav. Fragr. J., 8, 139 (1993).

15. M. Taherkhani, A. Rustaiyan and H. Nahrevanian, Asian J. Chem., 24, 1591 (2012)

16. M.M. Barazandeh, J. Essent. Oil Res., 15, 259 (2003).

17. T. Dob and T. Benabdelkader, J. Essent. Oil Res., 18, 685 (2006)

18. M.M. Barazandeh, J. Essent. Oil Res., 15, 414 (2003).

19. M. Gholami, A. Azizi and P. Salehi, Asian J. Chem., 17, 2229 (2005).

20. L. Ahmadi and M. Mirza, J. Essent. Oil Res., 13, 30 (2001).

21. Y. Li, H.-B. Hu, X.-D. Zheng, J.-H. Zhu and L.-P. Liu, 24, 1091 (2012).

22. J.A. Marco, J.F. Sanz, F. Sancenon, A. Rustaiyan and M. Saberi, Phytochemistry, 32, 460 (1993).

23. Y. Massada, Analysis of Essential Oil by Gas Chromatography and Mass Spectrometry, John Wiley \& Sons, New York (1976).

24. R.P. Adams, Identification of Essential Oil Components by Gas Chromatography/Quadruple Mass Spectroscopy Allured Publishing Corp., Carol Stream, IL (2000).
25. S.K. Ramaswami, P. Briscese, R.J. Gargiullo and T. Vonngeldern, in eds.: B.M. Lawrence, B.D. Mookerjee and B.J. Willis, A World Perspective, Elsevier, Amsterdam, p. 951 (1988).

26. H. Van Den Dool and P.D. Kratz, J. Chromatogr., 11, 463 (1963).

27. C.M. Collins and P.M. Lyne, Microbiological Methods, London, Butterworths (1987).

28. P.R. Murray, E.J. Baron, M.A. Pfaller, F.C. Tenover and R.H. Yolke, Manual of Clinical Microbiology, Washington, DC, ASM, edn. 7 (1995).

29. National Committee for Clinical Laboratory Standards, Approved Standard M100-S10, MIC Testing Supplemental Tables, National Committee for Clinical Laboratory Standards (2000).

30. M. Burits and F. Bucar, Phytother. Res., 14, 323 (2000).

31. M.S. Taga, E.E. Miller and D.E. Pratt, J. Am. Oil Chem. Soc., 61, 928 (1984).

32. H.S. Choi, H.S. Song, H. Ukeda and M. Sawamura, J. Agric. Food Chem., 48, 4156 (2000).

33. E.R. Hendry, T. Worthington, B.R. Conway and P.A. Lambert, J. Antimicrob. Chemother, 64, 1219 (2009).

34. M.M. Cowan, Clin. Microbiol. Rev., 12, 564 (1999).

35. G. Ruberto and M.T. Baratta, Food Chem., 69, 167 (2000). 